\title{
Preliminary Results of Anthropogenic Seismicity Monitoring in the Region of Song Tranh 2 Reservoir, Central Vietnam
}

\author{
Jan WISZNIOWSKI ${ }^{1}$, Nguyen Van GIANG ${ }^{2}$, Beata PLESIEWICZ ${ }^{1}$, \\ Grzegorz LIZUREK ${ }^{1}$, Dinh Quoc VAN ${ }^{2}$, Le Quang $\mathrm{KHOI}^{2}$, \\ and Stanisław LASOCKI ${ }^{1}$
${ }^{1}$ Institute of Geophysics, Polish Academy of Sciences, Warsaw, Poland e-mail: jwisz@igf.edu.pl (corresponding author)
${ }^{2}$ Institute of Geophysics, Vietnam Academy of Science and Technology, \\ Hanoi, Vietnam; e-mail: giangnv@igp-vast.vn
}

\begin{abstract}
Song Tranh 2 hydropower plant and the reservoir containing backed up water are located in the Quang Nam province (Central Vietnam). The region experiences unusual seismic activity related to the reservoir impoundment, with earthquakes of magnitude up to 4.7. In result of cooperation between the Institute of Geophysics, Vietnam Academy of Sciences and Technology and the Institute of Geophysics, Polish Academy of Sciences a seismic network has been built to facilitate seismic monitoring of the Song Tranh 2 area. The network, operating since August 2013, consists of 10 seismic stations. Here we show that the network is sufficient for advanced data processing. The first results of monitoring of the earthquake activity in Song Tranh 2 area in the period between 2012 and 2014, especially the completeness of catalogs, study and comparisons between water level and the seismic activity suggest direct connection between reservoir exploitation and anthropogenic seismicity.
\end{abstract}

Key words: reservoir induced seismicity, seismic network, source parameters, focal mechanism, completeness of catalogs. 


\section{INTRODUCTION}

Earthquakes can be caused by natural processes (tectonic movement, volcanic activity, etc.) or by human technological activity. The earthquakes associated with human activity are called Induced Seismicity (IS). Under certain suitable geological conditions, technological operations can trigger or induce earthquakes. Induced seismicity includes cases such as seismicity associated with an impoundment of surface water reservoirs, underground mining, large-scale surface quarrying, high-pressure fluid injection for geothermal power generation and a conventional and unconventional hydrocarbon exploitation, underground storage of fluids, removal of underground fluids, and underground explosions.

Association of earthquakes with impounding of artificial water reservoirs was for the first time pointed out by Carder (1945) for lake Mead in the United States. The number of reported cases of reservoir-induced earthquakes has steadily grown since then (Gupta 1992). The largest reservoir impoundment-triggered earthquakes exceeded magnitude 6. Occurrence of a damaging 6.3 magnitude earthquake at Koyna dam, India was in December 1967. Hoa Binh province, Northern Vietnam, is a case of reservoir triggered seismicity where in 1989 an earthquake of magnitude 4.9 took place (Gupta 2011).

Simpson (1976) and Gupta (1985) found that, in some locations, the Reservoir Induced Seismicity (RIS) occurs early after reservoir impoundment, whereas in other places the earthquake excitation occurs a number of years after the lake began to be filled. Based on such observations, Simpson (1986) and Simpson et al. (1988) have classified RIS into two types: rapid response type and delayed response type. The rapid response may be associated with changes in elastic stress due to the load of the reservoir. Examples of such a response (Simpson et al. 1988) are lakes Monticello, Manic 3, Nurek, Kariba, and Tehri (Choudhury et al. 2013). In contrast with the rapid response RIS phenomenon, in the delayed response RIS events occur relatively later after the reservoir filling. Some examples are Aswan, Koyna, and Oroville (Simpson et al. 1988). In such reservoirs the pore pressure at hypocentral depths can rise slowly, with the diffusion of water from the lake. In the delayed response class a number of water level changes can take place before the earthquake activity is enhanced. In some places, like Koyna and lake Mead, the rapid and the delayed response appeared.

The present paper considers the case of reservoir triggered seismicity in the Song Tranh 2 (STH2) reservoir region, located in the Quang Nam province in Central Vietnam. The largest earthquake, of magnitude 4.7, which occurred on 15 November 2012, was felt by people and damaged structures 
of buildings in the surrounding areas. Currently a constant seismic activity is observed in the $\mathrm{STH} 2$ region.

On 4 April 2013, there was concluded an Agreement for Research Cooperation between the Institute of Geophysics, Vietnam Academy of Science and Technology (IGP VAST) and the Institute of Geophysics, Polish Academy of Sciences (IGP PAS). The purpose of this Agreement for Research Co-operation is to provide a framework for promotion of co-operative research between IGP VAST and IGP PAS in the field of RIS research. This includes, in particular, the installation of seismic stations, seismic monitoring and processing, analyzing and interpreting the seismological data of reservoir STH2 area in Bac Tra My district and surrounding areas in Quang Nam province in Central Vietnam. Special emphasis is focused on investigation of the focal mechanism of events and seismic hazard estimation. The first results of the monitoring campaign are presented below together with a preliminary interpretation of the observed seismic pattern.

\section{SEISMIC ACTIVITY CAUSED BY FILLING OF THE SONG TRANH 2 RESERVOIR}

The natural seismic activity of the STH2 region is very low. From the earthquake sources such as operational history, international data, as well as recorded by seismic stations in Central Vietnam, it has been found that, in the period from 1775 to 1992 , only 13 events in this area have been found in both historical and instrumental world seismological data. Out of these 13, there was only one earthquake in 1715 which was located near the hydropower reservoir (Fig. 1) and its magnitude was about 4.7 (Thuy et al. 2003).

The filling of STH2 reservoir started in November 2010. The reservoir volume is 740 million $\mathrm{m}^{3}$ and its height is $196 \mathrm{~m}$. The water level began to increase slowly from about $153 \mathrm{~m}$ in early January 2011 to about $159.4 \mathrm{~m}$ on 17 February 2011 and then it was reduced to approximately $140 \mathrm{~m}$ on $20 \mathrm{Ju}-$ ly 2011. Filling of reservoir was recommenced on 20 August 2011. On 27 October 2011 the maximum water level of $175 \mathrm{~m}$ was reached. The water level around $175 \mathrm{~m}$ was kept until February 2012, when it was quickly reduced to the level of $157.64 \mathrm{~m}$, because of some technical problems unconnected with seismicity. In May 2012 it was further decreased to $139.3 \mathrm{~m}$. After that, it was kept close to $140 \mathrm{~m}$ to the end of September 2013. Fig. 2 shows the relationship between the reservoir water level variation and earthquakes.

During the period from the end of 2010, the analysis of seismic data recorded by 2 Vietnam national seismic stations, located in Binh Dinh and Hue (about 120-160 km from SH2), indicated several earthquakes whose epicenters were located in the province of Quang Nam (Fig. 1). Up to the beginning of 2011, the seismic activity in this area increased significantly. From 


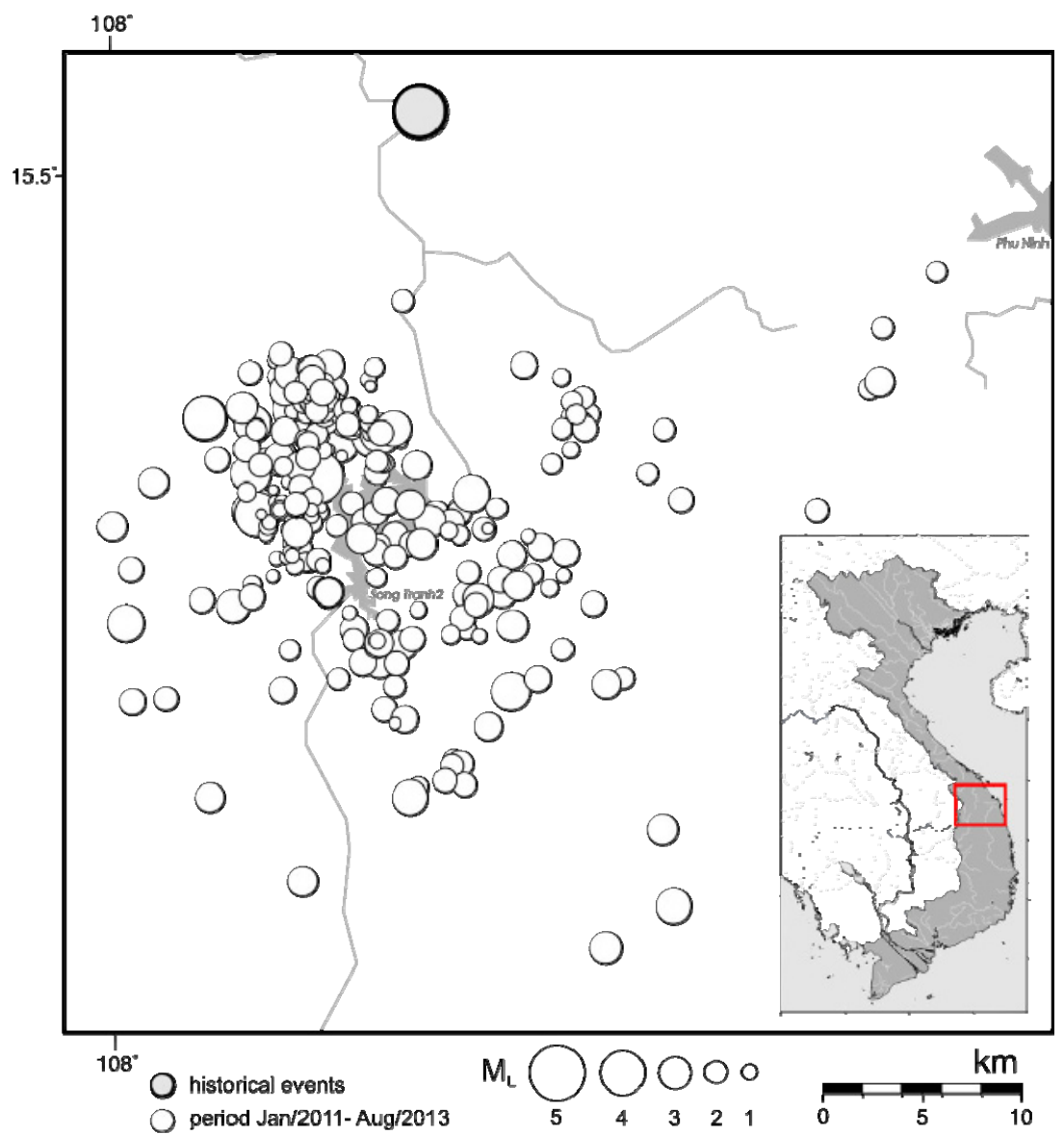

Fig. 1. Location of historical events and events from the period January 2011 August 2013 grouped around the STH2 reservoir.

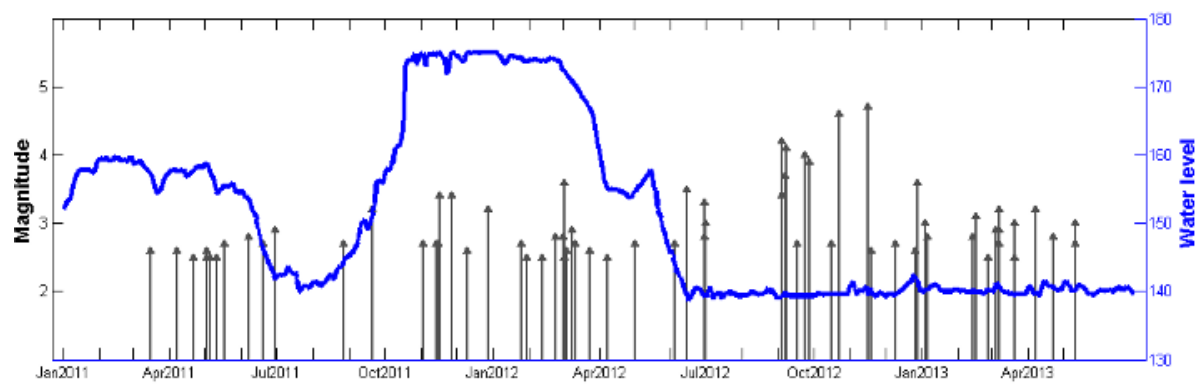

Fig. 2. The water level in the STH2 reservoir and seismic activity around the region with events with magnitude higher than 2.5 in the period from January 2011 to July 2013. 
March 2011 also stronger events began to occur (Fig. 2). Two strongest took place on 22 October and 15 November 2012, and their magnitudes were $M_{L}=4.6$ and 4.7 , respectively. They were felt by people and caused minor damage to housing in the area.

\section{GEOLOGY AND TECTONICS OF THE SONG TRANH 2 REGION}

The STH2 dam and reservoir are located in Bac Tra My district in Quang Nam province, central part of Vietnam (Fig. 3). It is one of a few dams planned to be set up on the river Tranh. Geographic coordinates of the dam are: $108.1472^{\circ} \mathrm{E}$ and $15.3336^{\circ} \mathrm{N}$.

The central and south Vietnamese continental margin forms the transition from the continental Indochina Block to the East Sea underlain partially by oceanic crust (Fyhn et al. 2009, Nam 1995). STH2 reservoir is located on boundary zone between Truongson and Kontum structural blocks. The first constitutes NW-SE trending Paleozoic fold system the latter is the uplifted Archean massif.

Target area constitute SE end of NW-SE trending left-lateral Cenozoic Ailao Shan-Red river shear zone. Tectonics of the area is dominated by system of W-E trending thrusts, with tectonic transport to the south: the Tam Ky-Phuoc Son, Tra Bong, and Hung Nhuong - Ta Vi (Fig. 3). STH2 is underlain by gneiss metamorphic complex Kham Duc - Nui Vu of Hung Nhuong - Ta Vi thrust.

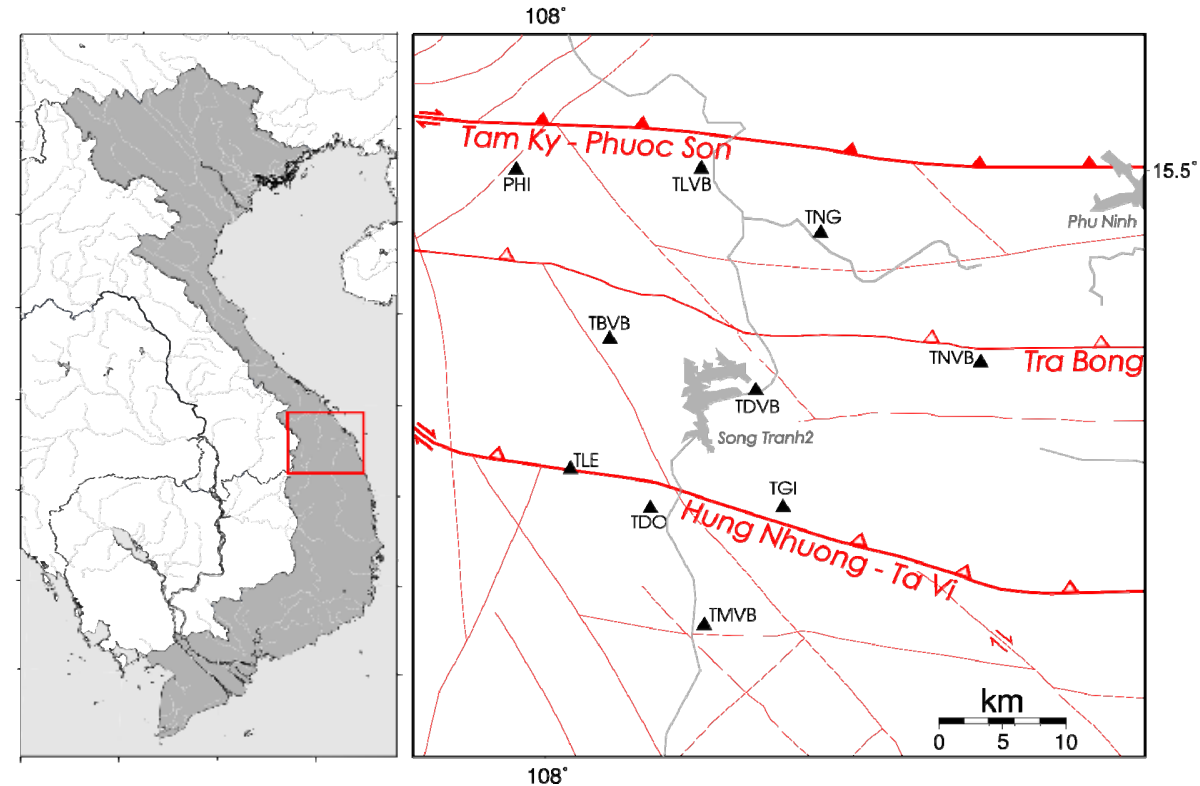

Fig. 3. Tectonic setting of the STH2 reservoir area. 
There were reports of only several tremors since 17th century in the area of central Vietnam, which indicates that the whole region can be recently regarded as of moderately seismic activity (Phach and Chinh 1995).

\section{SEISMIC MONITORING OF THE SONG TRANH 2 REGION}

The recording of seismicity in STH2 area has had three phases:

\section{Phase I - from January 2011 to October 2012}

At the beginning of the reservoir filling, the STH2 area was monitored by two seismic stations located in Binh Dinh and Hue, away from the reservoir. Therefore, they were capable of recording earthquakes from the STH2 region with magnitudes from about 2.0 up. From January 2011 to September 2012, these two stations recorded more than 100 earthquakes in the Bac Tra My and surroundings, having magnitude $M=1.8 \div 4.2$ (Fig. 2 and 9). Basic parameters of the stations in Binh Dinh and Hue are presented in Table 1.

Table 1

Seismic stations in phase I

\begin{tabular}{|c|l|c|c|c|c|c|}
\hline \multirow{2}{*}{ No. } & \multirow{2}{*}{$\begin{array}{c}\text { Station } \\
\text { name }\end{array}$} & \multirow{2}{*}{ Code } & \multicolumn{2}{|c|}{ Coordinates } & Elevation & Logger / seismometer \\
\cline { 4 - 5 } & & $\varphi\left[{ }^{\circ} \mathrm{N}\right]$ & $\lambda\left[{ }^{\circ} \mathrm{E}\right]$ & & \\
\hline 1 & Binh Dinh & BDVB & 13.8645 & 109.1111 & 61 & Q330HRS / STS-2 \\
2 & Hue & HUBV & 16.4155 & 107.5689 & 20 & Q330 / Trillium-40 \\
\hline
\end{tabular}

\section{Phase II - from October 2012 to August 2013}

Phase II began when IGP VAST deployed a five station seismograph network in the vast STH2 region. There were stations in Tra Doc, Tra Bui, Tra $\mathrm{Nu}$, Tra Mai, and Tien Lanh (Table 2). The stations were equipped with Guralp seismometers and the SAMTAC logger and one Trillium-40 seismometer with the Q330 logger (Tra Doc station). The network made it possible to record events with magnitude less than 2.0 and to determine earthquake parameters such as epicentral locations more accurately.

\section{Phase III - from August 2013 - new joint seismic network}

In August 2013 a team from IGP VAST together with a team from IGP PAS installed 10 seismic stations. The integrated seismic network was called VERIS (ViEtnam Reservoir Induced Seismicity). Stations provided by IGP PAS were equipped with short-period seismometers Lennartz LE-3DLite $(1 \mathrm{~s})$, whereas station provided by IGP VAST were equipped with long- 
Table 2

Seismic stations of VERIS network (stage III)

\begin{tabular}{|c|c|c|c|c|c|c|}
\hline \multirow{2}{*}{ No. } & \multirow{2}{*}{$\begin{array}{l}\text { Station } \\
\text { name }\end{array}$} & \multirow{2}{*}{ Code } & \multicolumn{2}{|c|}{ Coordinates } & \multirow{2}{*}{$\begin{array}{c}\text { Elevation } \\
{[\mathrm{m}]}\end{array}$} & \multirow{2}{*}{ Logger / Seismometer } \\
\hline & & & $\varphi\left[{ }^{\circ} \mathrm{N}\right]$ & $\lambda\left[{ }^{\circ} \mathrm{E}\right]$ & & \\
\hline 1 & Tien Ngoc & TNG & 15.4472 & 108.2038 & 97 & NDL / LE-3Dlite \\
\hline 2 & Tra Don & TDO & 15.2432 & 108.0849 & 185 & NDL / LE-3Dlite \\
\hline 3 & Tra Leng & TLE & 15.2722 & 108.0225 & 192 & NDL / LE-3Dlite \\
\hline 4 & Tra Giac & TGI & 15.2400 & 108.1756 & 328 & NDL / LE-3Dlite \\
\hline 5 & Phuoc Hiep & PHI & 15.4954 & 107.9776 & 56 & NDL / LE-3Dlite \\
\hline 6 & Tra Doc & TDVB & 15.3342 & 108.1634 & 113 & $\begin{array}{c}\text { Guralp CMG-6TD } \\
\text { (Q330 / Trillium-40) }\end{array}$ \\
\hline 7 & Tra Bui & TBVB & 15.3667 & 108.0503 & 224 & $\begin{array}{l}\text { Guralp CMG-6TD } \\
\text { (SAMTAC / Guralp) }\end{array}$ \\
\hline 8 & Tra Nu & TNVB & 15.3564 & 108.3268 & 126 & $\begin{array}{l}\text { Guralp CMG-6TD } \\
\text { (SAMTAC / Guralp) }\end{array}$ \\
\hline 9 & Tra Mai & TMVB & 15.1480 & 108.1202 & 202 & $\begin{array}{l}\text { Guralp CMG-6TD } \\
\text { (SAMTAC / Guralp) }\end{array}$ \\
\hline 10 & Tien Lanh & TLVB & 15.4958 & 108.1200 & 325 & $\begin{array}{l}\text { Guralp CMG-6TD } \\
\text { (SAMTAC / Guralp) }\end{array}$ \\
\hline
\end{tabular}

Note: seismometers and recorders used in phase II are in brackets.

period seismometers Guralp CMG-6TD (30 s). Signals from Lennartz seismometers were recorded by Net Data Logger (NDL), which served in the project with sampling rate of 100 sps and dynamics $132 \mathrm{~dB}$. Seismometers Guralp have on-board digitizer of $130 \mathrm{~dB}$ dynamics. Seismic signal is sampled with a frequency of 100 sps. Both systems are appropriate to measure local and regional seismicity, as in such a case most of seismic waves' power is in the range of a few $\mathrm{Hz}$, whereas Guralp stations are more suitable for the largest events in the STH2 region because their frequency band includes more low frequencies. The responses of both recording systems are presented in Fig. 4. Seismometers Lennartz LE-3DLite were installed in new stations, whereas Guralp stations replaced the previously working equipment (Table 2).

Positions of new five stations are determined by the location of the previous seismic events. They supplement earlier five stations and provide moderately complete azimuthal coverage (Fig. 10). It allows for more accurate moment tensor estimation.

The final choice of stations was preceded by ground-penetrating radar (GPR) measurements (Giang et al. 2010). The goal of this study was to find 


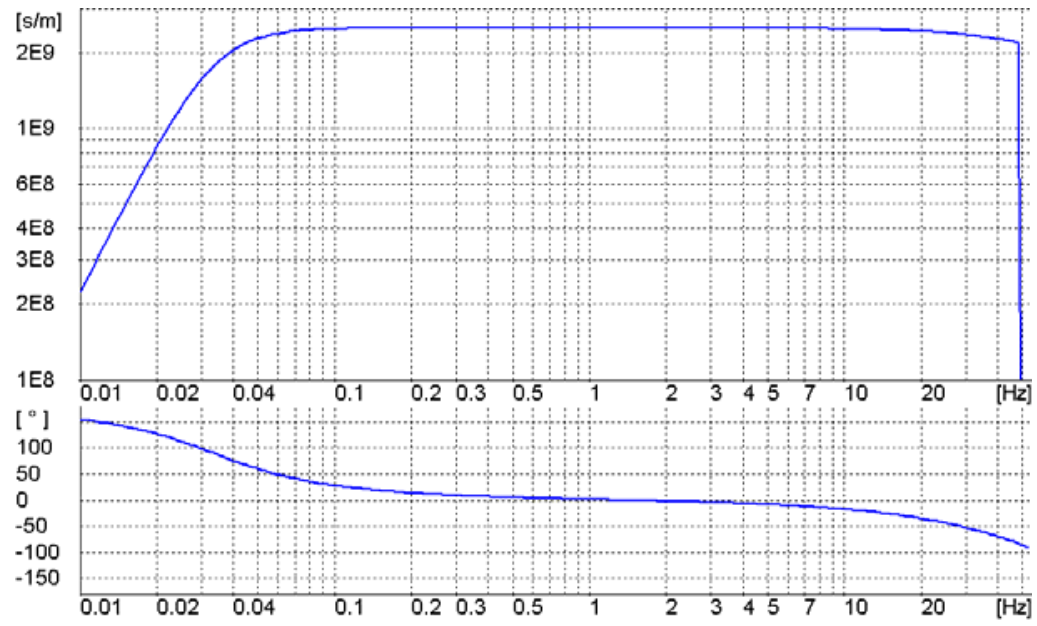

(a)

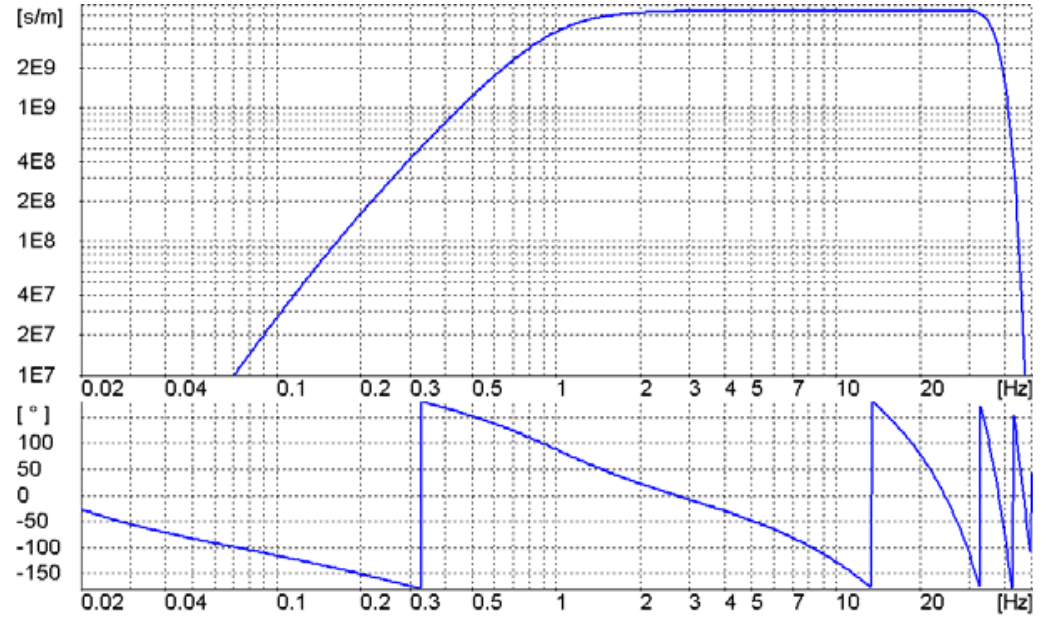

(b)

Fig. 4. The frequency-amplitude-phase response of: (a) the Guralp CMG-6TD seismometer, and (b) the Lennartz LE-3Dlite seismometer with the NDL recorder.

the location and foundations of stations on the bedrock. The GPR measurement helped assess the cohesiveness of the substratum, whether the rock is fissured or separated from the bedrock. Good foundation of seismic stations allows reducing the noise and improving detection of seismic events. It was important, because stations had to be located into residential places for security sake. The Power Spectral Densities (PSD) of seismic noises are presented in Fig. 5. We did not notice differences in noise between day and night and between Dry and Wet Seasons. 

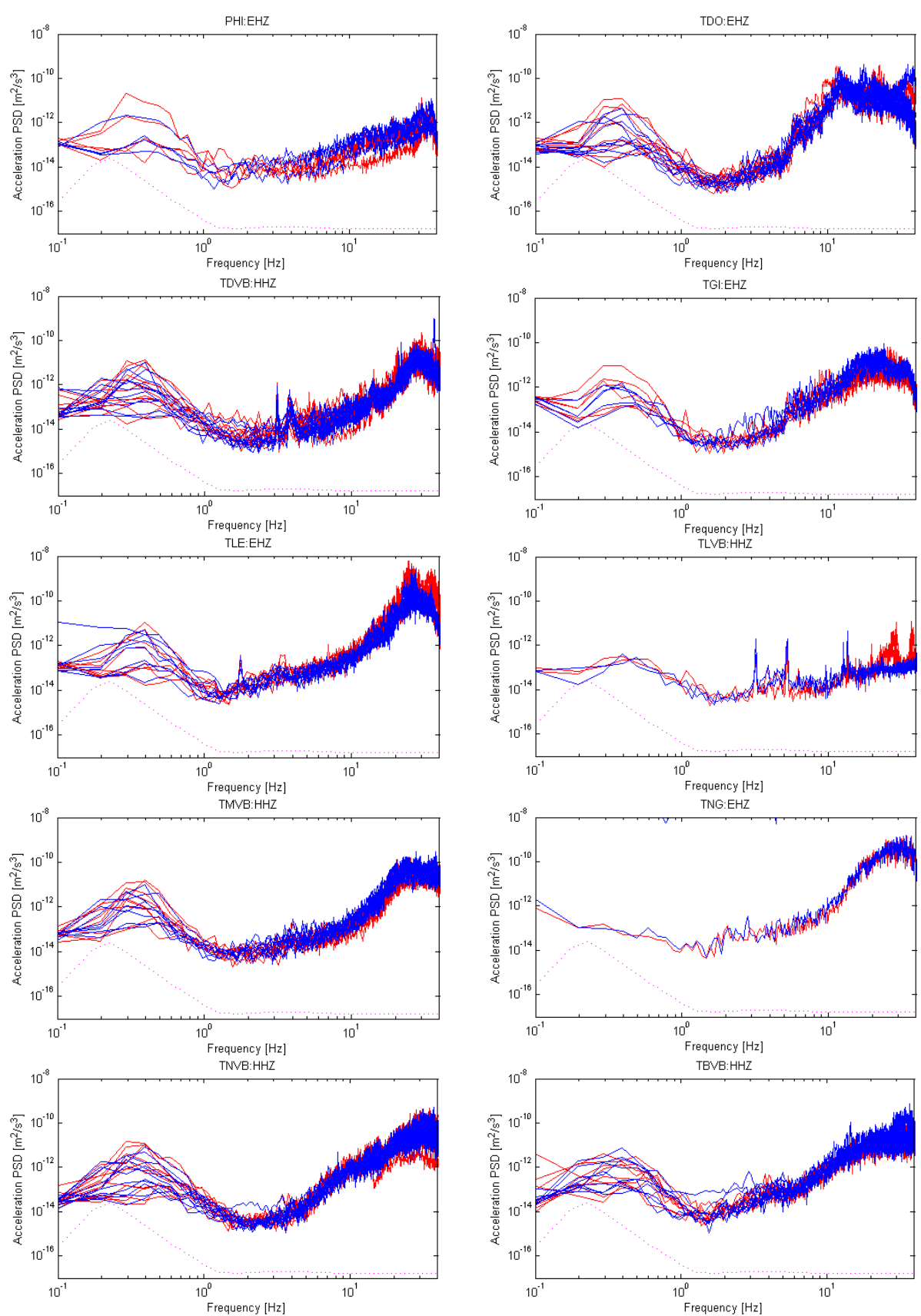

Fig. 5. The Power Spectral Densities (PSD) of seismic noise in STH2 network stations. In most of the stations the PSD is taken from both Dry and Wet Seasons. Red lines describe PSD in day whereas blue ones show noise in night. The dotted line is the PSD of Peterson's (1982) Low Noise Model. 


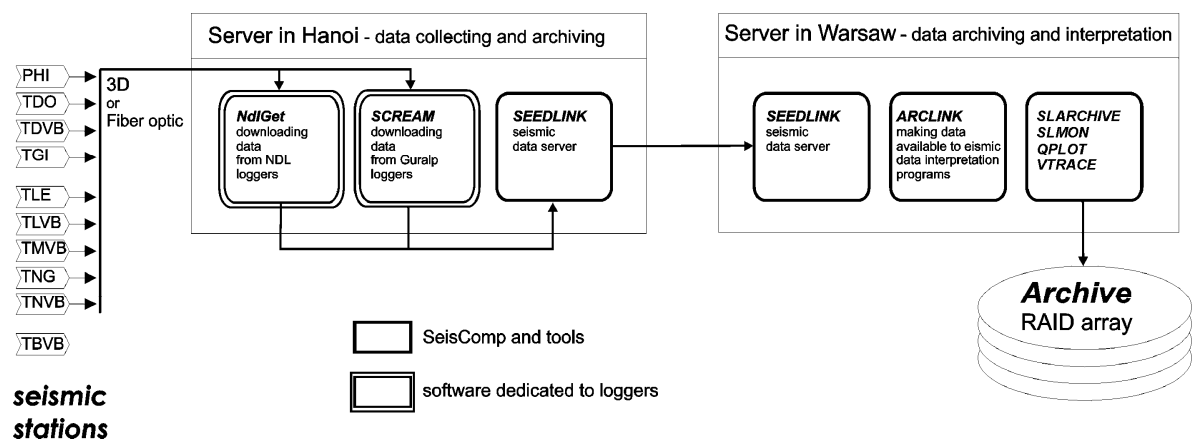

Fig. 6. Acquisition and archive system with data flow.

Seismic stations are connected to IGP VAST in Hanoi either by fiber optic or by $3 \mathrm{G}$ connections in Virtual Personal Network. Seismic data are transmitted on-line and stored both in Hanoi and Warsaw (Fig. 6). The system based on SeisComP (www.seiscomp3.org/wiki/doc) software is applied for collecting and archiving the data. Additional components like modules for communication with the stations have been added to adapt the system to the project requirements.

Data from Guralp stations is downloaded by SCREAM program and then transmitted to SeisComP, which is running at the same server. Data from NDLs is copied by FTP every two minutes to the same SeisComP. Seismic data from server in Hanoi is transmitted to Warsaw where waveforms are stored on a RAID matrix. The whole system combines earlier solutions (Lizurek et al. 2013, Trojanowski et al. 2015). It allows visualizing data in real time, saving and studying them as well as monitoring and controlling the data acquisition system.

Since 24 August 2013, seismic bulletins and catalogs for STH2 region are based on VERIS network. LocSAT application with the IASP91 traveltime tables provides estimates of the origin time, epicentral location, and depth from an iterative least-squares inversion of travel time, slowness, and/or azimuth (Bratt and Bache 1988, Bratt and Nagy 1991).

\section{THE EXAMPLES OF FOCAL MECHANISMS OF EVENTS FROM SONG TRANH 2 REGION}

Moment tensor estimates for STH2 earthquakes recorded by the VERIS network have been obtained from inversion of the $P$-wave amplitudes in time domain (Wiejacz 1992, Awad and Kwiatek 2005) using FOCI 3.0 software (Kwiatek 2013). The registered first onsets were of direct $P$ wave according to the velocity model of the STH2 area. The velocity determined for the direct waves was $5.9 \mathrm{~km} / \mathrm{s}$ upon the velocity model from Table 3 (Son 1995). 
Table 3

Velocity model for Song Tranh 2 region

\begin{tabular}{|c|c|}
\hline $\begin{array}{c}\text { Depth } \\
{[\mathrm{km}]}\end{array}$ & $\begin{array}{c}P \text {-wave velocity } \\
{[\mathrm{km} / \mathrm{s}]}\end{array}$ \\
\hline $0-17$ & 5.9 \\
$17-33$ & 6.7 \\
$33-97$ & 8.0 \\
\hline
\end{tabular}

The direct waves were recorded on 8 stations of VERIS network. The input parameters were the amplitude and polarity of the first $P$-wave displacement pulses. According to Fitch et al. (1980) the recorded displacement for the vertical component of the $P$-wave phase is:

$$
U_{z}^{P}(x, t)=\frac{1}{4 \pi \rho \alpha^{3} r}\left[\bar{\gamma} M \dot{s}\left(t-\frac{r}{\alpha}\right) \bar{\gamma}\right] l_{z},
$$

where $\rho$ is the average density, $r$ is the source-receiver distance, $\alpha$ is the average velocity of $P$ wave, $M$ is the seismic moment, $l_{z}$ is the cosine of the incidence angle, and $\bar{\gamma}$ is the take-off angle. The Source Time Function (STF) was based on the Haskell's source model (Haskell 1953):

$$
\dot{s}=\begin{array}{cc}
1 / T, & 0<t<T, \\
0, & \text { elsewhere, }
\end{array}
$$

where $T$ is the rupture time.

Moment tensor is obtained by solving of a set of $N$ equations of type 1 , where $N$ is the number of stations that recorded the event. Six independent components of moment tensor require minimum six equations, and in the presented case we could use eight. All, full moment tensors, only deviatoric, and only DC solutions were calculated. L2 norm was used to determine a solution misfit (Wiejacz 1992, Awad and Kwiatek 2005). The results of inversion are presented in Table 4 and in Fig. 7. The azimuthal coverage was sparse and the number of available recordings was at the limit of the methodological requirements, which obviously influenced the inversion results. Nevertheless, those first two focal mechanism solutions provide a preliminary insight into tectonic properties of earthquake generation in the vicinity of STH2.

Additionally, the fault plane solutions were also calculated with use of HASH software. In this approach only polarities of $P$-wave onsets are used for constraining the fault plane orientations. All of the polarities have equal weight and the algorithm used in this technique uses a grid-search to deter- 
Table 4

Seismic moment, moment magnitude, and nodal planes of the two studied events

\begin{tabular}{|c|c|c|c|c|c|c|}
\hline Event & $\begin{array}{c}\text { Seismic } \\
\text { moment } \\
{[\mathrm{Nm}]}\end{array}$ & $M_{W}$ & $\begin{array}{c}\text { MT nodal } \\
\text { plane A }\end{array}$ & $\begin{array}{c}\text { MT nodal } \\
\text { plane B }\end{array}$ & $\begin{array}{c}\text { Fault plane } \\
\text { nodal plane A }\end{array}$ & $\begin{array}{c}\text { Fault plane } \\
\text { nodal plane B }\end{array}$ \\
\hline 3 Sep 2013 & $5.01 \times 10^{13}$ & 3.1 & $33^{\circ} / 55^{\circ} /-82^{\circ}$ & $200^{\circ} / 36^{\circ} /-101^{\circ}$ & $6^{\circ} / 76^{\circ} /-138^{\circ}$ & $263^{\circ} / 50^{\circ} /-19^{\circ}$ \\
31 Oct 2013 & $2.85 \times 10^{12}$ & 2.2 & $190^{\circ} / 78^{\circ} / 72^{\circ}$ & $69^{\circ} / 22^{\circ} / 147^{\circ}$ & $298^{\circ} / 78^{\circ} /-143^{\circ}$ & $199^{\circ} / 54^{\circ} /-15^{\circ}$ \\
\hline
\end{tabular}

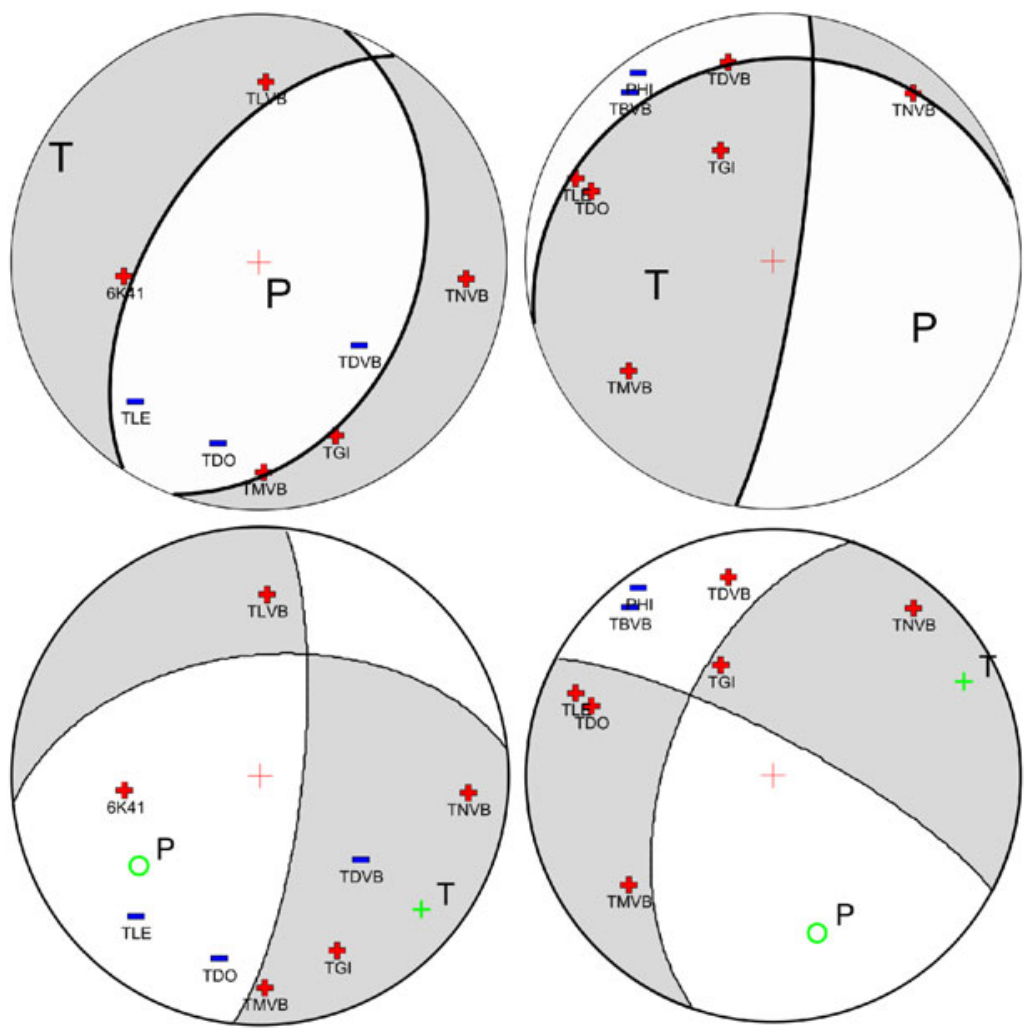

Fig. 7. Mechanism of two events from STH2 region. From left to right: $M_{L} 3.2$ on 3 September 2013 and $M_{L} 1.8$ on 31 October 2013. The codes and signs denote the station location and polarization on focal sphere. The upper row shows the results from the MT and the lower row the optimal results of fault plane solution.

mine $P$-wave polarity first-motion focal mechanisms. For each earthquake, a set of acceptable mechanisms is found. The spread of the acceptable mechanisms determines the uncertainty and the assigned solution quality. The al- 
gorithm allows for minimum $7 P$-wave onsets and there is up to 2 wrong polarity picks allowed for the search of optimal solution. The set of acceptable mechanisms takes into account the uncertainty in polarity measurements, event location, and takeoff angle (Hardebeck and Shearer 2002).

A comparison of obtained results is shown in Fig. 7. It is clearly visible that the MT inversion results (upper row of Fig. 7) better constrained the nodal planes according to polarities of the stations. Both methods suffer from poor azimuthal coverage and the quality of solutions. In both methods the uncertainty of fault plane orientations is high, with about 50 degrees of uncertainty of strike and rake, and about 15 degrees of uncertainty of dip. Taking the above issues into account, the MT inversion seems a more reasonable approximation of the mechanisms from the available data. Despite all above-mentioned limitations, the obtained mechanisms are valuable information about the seismic process in the Song Tranh 2 reservoir area.

Source mechanism of the 3 September 2013 event reveals normal faulting with strike azimuth NNE-SSE and moderate dip angle of about 40-50 degrees (Fig. 7). Nodal plane orientations are parallel to the Tra Bong thrusting movement direction, but perpendicular to the strike of this main discontinuity. In the area of the event location, the main discontinuities are not in agreement with the nodal planes orientation. Moreover, the principal stress regime indicates strike-slip faulting, while the inversion results indicate the normal faulting. The tension axis orientation is similar to the main strike slip stress pattern in this area, but the polarities and amplitudes of the first $P$-wave pulses determine the focal mechanism results as a normal fault. The quality of the solution is limited by the number of stations available and their azimuthal coverage. There were only 8 stations with good signal to noise ratio, which were used in inversion. The azimuthal coverage was good in the southern half of the focal sphere, but only one station was available in the northern half of the focal sphere.

The source mechanism obtained for the 31 October 2013 event suggests reverse faulting with strike almost N-S or W-E. The second nodal plane orientation is almost similar to the Hung Nhuong - Ta Vi thrust, but the main regime of this area is strike-slip, which is not in agreement with the obtained focal mechanism. Once again, the station azimuthal coverage was not sufficient, especially in SW quadrant of the focal sphere, where not even a single station was available, while 6 out of 8 available stations were covering the NW quadrant.

Due to the limited number of stations, the results should be treated as the fault plane solution, rather than the full MT. The obtained results are not sufficient yet for any general conclusions about the stress or tectonic regime of the process leading to the seismicity of the STH2 reservoir vicinity. Nevertheless the focal mechanism solution show that the seismic process in the 
STH2 dam vicinity cannot be interpreted as purely tectonic. Both locations and mechanisms of the events indicate that the stress changes followed the dam impoundment may play a role in the seismogenic process.

\section{COMPLETENESS OF CATALOGS FOR THE VERIS NETWORK}

Completeness magnitude $\left(M_{C}\right)$ of earthquake catalogs is the lowest magnitude at which all the earthquakes are detected in selected space and time volume. The completeness of catalogs has been estimated based on shape of frequency-magnitude distribution (FMD) of detected events in the selected region as well as by other techniques (Mignan and Woessner 2012): maximum curvature (MAXC) (Wyss et al. 1999, Wiemer and Wyss 2000), entire magnitude range (EMR) (Woessner and Wiemer 2005), and study of the $b$-value stability of Gutenberg-Richter (Gutenberg and Richter 1944) model as a function of cut off magnitude (MBS) (Cao and Gao 2002).

The MAXC method estimates $M_{C}$ as the point of the maximum curvature by computing the maximum value of the first derivative of the frequencymagnitude curve (cumulated FMD). In practice, this matches the group of magnitudes with the highest frequency of events in the FMD. This technique requires fewer events than other techniques to reach a stable result; however, it underestimates sometimes the $M_{C}$ value (Wiemer and Wyss 2000, Woessner and Wiemer 2005). Some modifications of this method are provided by Leptokaropoulos et al. (2013).

In EMR technique the entire observed magnitude range is used to estimate the $M_{C}$. Woessner and Wiemer (2005) proposed a model consisting of two parts: the Gutenberg-Richter law for the complete part, and the cumulative normal distribution for the incomplete part of the FMD. They tested also log-normal and Weibull distributions.

Cao and Gao (2002) estimated $M_{C}$ using the stability of the $b$-value as a function of cut-off magnitude $M_{C o}$, named as MBS by Woessner and Wiemer (2005). The $M_{C}$ is defined as the magnitude for which the changes in $b$-value $(\Delta b)$ is smaller than 0.03 . It is based on the assumption that estimation of $b$ increases for $M_{C_{0}}<M_{C}$ and remains constant for $M_{C_{0}}>M_{C}$. This method does not produce good results in case of high variability of the FMD. Woessner and Wiemer (2005) used the $b$-value uncertainty $\delta b$ according to formula (Shi and Bolt 1982).

$$
\delta b=2.3 b^{2} \sqrt{\frac{\sum_{i=1}^{N}\left(M_{i}-\langle M\rangle\right)^{2}}{N(N-1)}},
$$

where $\langle M\rangle$ is the mean magnitude and $N$ is the number of events. 
Table 5

Estimates of completeness magnitude $\left(M_{C}\right)$ for events from the period 2013-2014

\begin{tabular}{|c|l|}
\hline Technique & $M_{C}$ \\
\hline MAXC & 0.8 \\
EMR & 1.1 \\
$M_{\min }$ & 0.12 \\
\hline
\end{tabular}

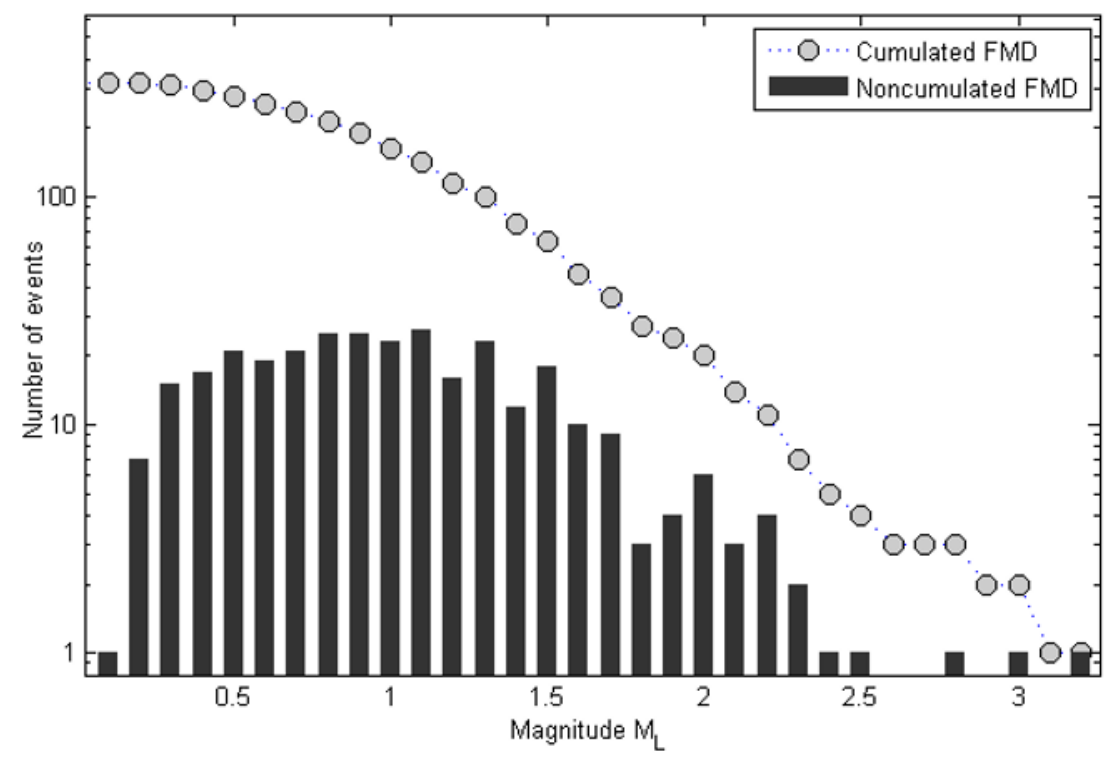

Fig. 8. FMD of events recoded in STH2 region in the period 2013-2014.

In the period from August 2013 to May 2014, the VERIS seismic network in central Vietnam recorded about 2000 earthquakes, from which approximately 350 were located. The values of $M_{C}$ calculated by different methods and minimum magnitude observed $\left(M_{\text {min }}\right)$ are presented in Table 5. Based on these values and on the shape of FMD of events recorded in the years 2013-2014 (Fig. 8) $M_{C}$ is assumed to be 1.1.

\section{SEISMIC ACTIVITY}

When installing the VERIS network, the lake level was $140 \mathrm{~m}$. Afterwards it began to increase with one sharp decline to the level of $149 \mathrm{~m}$ in November 2013. The level of water reached about $165.6 \mathrm{~m}$ at the beginning of 2014 . 
In the period from August 2013 to May 2014 about 2000 seismic events were detected; 359 of them were localized and magnitudes were calculated (Fig. 9a and 10). Figure 9a shows that in the consecutive phases the monitoring capacity increased, because of detection of smaller events. However, such events were not recorded in the beginning of seismic activity. Taking into consideration only events of magnitude $M \geq 2$ (Fig. 9b), there had not been noticed grown of seismic activity with the last increase of water level. A comparison of the seismic activity and the lake level does not suggest any straightforward correlation between these two parameters.

The network recorded also single small events close to the Phu Ninh reservoir northeast of the STH2 and weak seismicity in the whole area a few dozen kilometers away from the STH2 (Fig. 10).

In the period from 24 August 2013 to May 2014, earthquakes grouped in two locations: in the northern part of the reservoir, near the Tra Bong thrust, and to the south, aligned more or less parallel to the Hung Nhuong - Ta Vi thrust. This grouping is not indicated by locations of earthquakes recorded from January 2011 to July 2013, because of bigger error of their localization. Some earthquakes located next to the second reservoir (Phu Ninh), about $30 \mathrm{~km}$ away from STH2 reservoir, were also captured (Fig. 10).
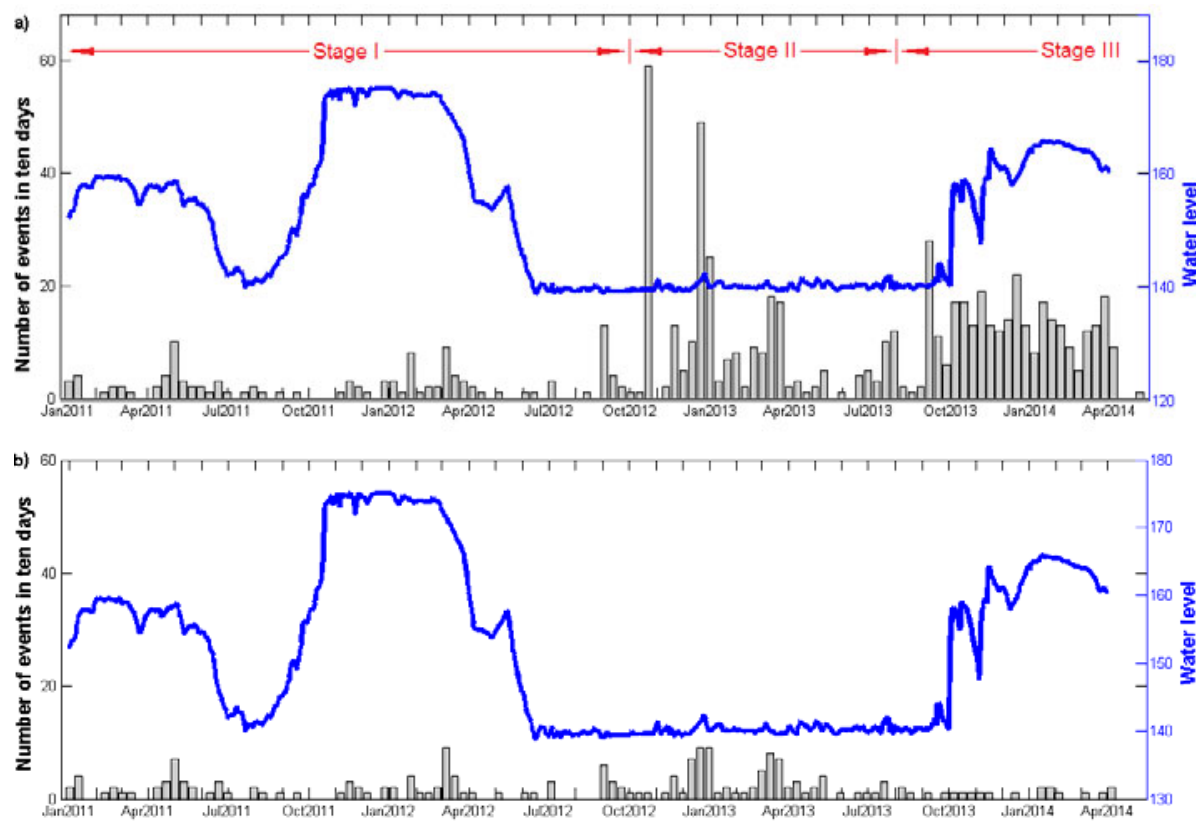

Fig. 9. The lake level of STH2 reservoir and seismic activity in the period January 2011 - May 2014 and: (a) the numbers of all localized events in 10 day periods, and (b) the numbers of events of magnitude $\geq 2$ in 10 day periods. 


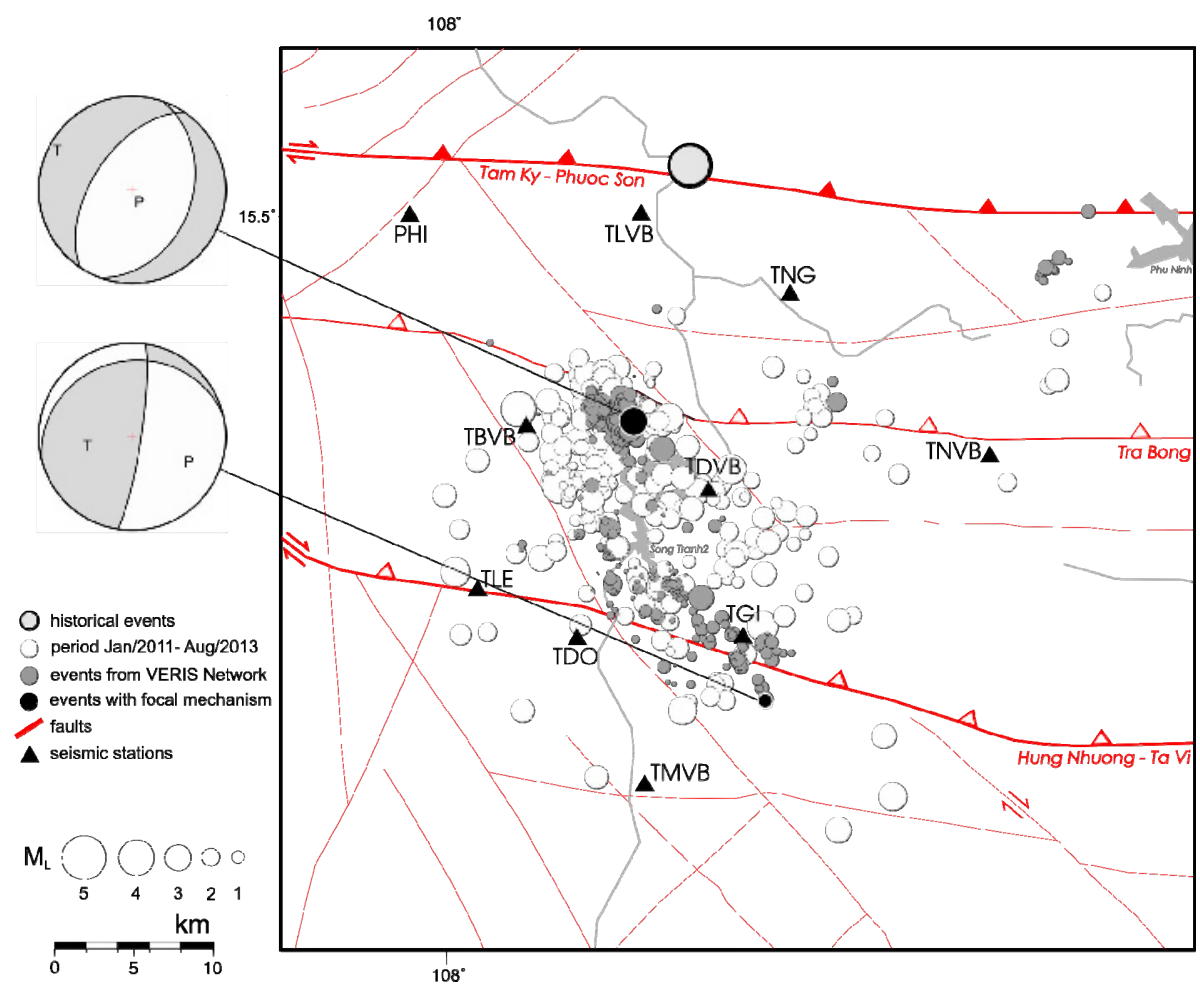

Fig. 10. Location of historical events and events from the period 2011-2014 grouped around the STH2 reservoir.

\section{CONCLUSIONS}

The installment of VERIS network increased significantly the earthquake detection and location capacity in the region of Song Tranh 2 reservoir. It also made it possible to calculate focal mechanisms and other source parameters. Unfortunately, the most intense seismic activity occurred earlier, when only two remote stations recorded seismic events. In order to monitor the whole development of seismicity triggered by reservoir impoundment, the monitoring should start before the beginning of filling the reservoir.

The fact that seismicity was practically absent in the studied region before the reservoir impoundment indicates that the earthquakes occurring since the impoundment are the effect of reservoir exploitation. More precise epicenter location facilitated by the VERIS network monitoring shows that earthquakes are grouped between the Tra Bong thrust and secondary faults of the Hung Nhuong - Ta Vi thrust. Analyses of mechanisms should soon provide better insight into the seismogenesis of the observed activity. 
So far no immediate correlation of the seismic activity with the lake level has been ascertained.

Acknowledgments. This work was done in the framework of the project IS-EPOS: Digital Research Space of Induced Seismicity for EPOS Purposes (POIG.02.03.00-14-090/13-00), funded by the National Centre for Research and Development in the Operational Program Innovative Economy in the years 2013-2015.

This work was partially supported within statutory activities No. 3841/E41/S/2015 of the Ministry of Science and Higher Education of Poland.

This research was carried out under financial supports of Ministry of Science and Technology of Vietnam, and Vietnam Academy of Science and Technology.

\section{References}

Awad, H., and G. Kwiatek (2005), Focal mechanism of earthquakes from June 1987 swarm in Aswan, Egypt, calculated by the moment tensor inversion, Acta Geophys. Pol. 53, 3, 275-291.

Bratt, S.R., and T.C. Bache (1988), Locating events with a sparse network of regional arrays, Bull. Seismol. Soc. Am. 78, 2, 780-798.

Bratt, S.R., and W. Nagy (1991), The LocSAT program, Science Applications International Corporation, San Diego.

Cao, A.M., and S.S. Gao (2002), Temporal variation of seismic b-values beneath northeastern Japan island arc, Geophys. Res. Lett. 29, 9, 48-1-48-3, DOI: 10.1029/2001GL013775.

Carder, D.S. (1945), Seismic investigations in the Boulder Dam area, 1940-1944, and the influence of reservoir loading on local earthquake activity, Bull. Seismol. Soc. Am. 35, 4, 175-192.

Choudhury, S., P.K. Gautam, and A. Paul (2013), Seismicity and reservoir induced crustal motion study around the Tehri Dam, India, Acta Geophys. 61, 4, 923-934, DOI: 10.2478/s11600-013-0125-1.

Fitch, T.J., D.W. McCowan, and M.W. Shields (1980), Estimation of the seismic moment tensor from teleseismic body wave data with applications to intraplate and mantle earthquakes, J. Geophys. Res. 85, B7, 3817-3828, DOI: $10.1029 / \mathrm{JB} 085 \mathrm{iB} 07 \mathrm{p} 03817$.

Fyhn, M.B.W., L.O. Boldreel, and L.H. Nielsen (2009), Geological development of the Central and South Vietnamese margin: Implications for the establishment of the South China Sea, Indochinese escape tectonics and Cenozoic volcanism, Tectonophysics 478, 3-4, 184-214, DOI: 10.1016/ j.tecto.2009. 08.002 . 
Giang, N.V., G. Marquis, and L.H. Minh (2010), EM and GPR investigations of contaminant spread around the Hoc Mon waste site, Vietnam, Acta Geophys. 58, 6, 1040-1055, DOI: 10.2478/s11600-010-0023-8.

Gupta, H.K. (1985), The present status of reservoir induced seismicity investigations with special emphasis on Koyna earthquakes, Tectonophysics 118, 3-4, 257-279, DOI: 10.1016/0040-1951(85)90125-8.

Gupta, H.K. (1992), Reservoir - Induced Earthquakes, Developments in Geotechnical Engineering, Vol. 64, Elsevier Science Publ., Amsterdam.

Gupta, H.K. (2011), Artificial water reservoir triggered earthquakes. In: H.K. Gupta (ed.) Encyclopedia of Solid Earth Geophysics, Springer, Dordrecht, 15-24, DOI: 10.1007/978-90-481-8702-7_15.

Gutenberg, B., and C.F. Richter (1944), Frequency of earthquakes in California, Bull. Seismol. Soc. Am. 34, 4, 184-188.

Hardebeck, J.L., and P.M. Shearer (2002), A new method for determining firstmotion focal mechanisms, Bull. Seismol. Soc. Am. 92, 6, 2264-2276, DOI: $10.1785 / 0120010200$.

Haskell, N.A. (1953), The dispersion of surface waves on multilayered media, Bull. Seismol. Soc. Am. 43, 1, 17-34.

Kwiatek, G. (2013), FOCI 3.0 software, http://induced.pl/foci (in Polish).

Leptokaropoulos, K.M., V.G. Karakostas, E.E. Papadimitriou, A.K. Adamaki, O. Tan, and S. Inan (2013), A homogeneous earthquake catalog for Western Turkey and magnitude of completeness determination, Bull. Seismol. Soc. Am. 103, 5, 2739-2751, DOI: 10.1785/0120120174.

Lizurek, G., B. Plesiewicz, P. Wiejacz, J. Wiszniowski, and J. Trojanowski (2013), Seismic event near Jarocin (Poland), Acta Geophys. 61, 1, 26-36, DOI: 10.2478/s11600-012-0052-6.

Mignan, A., and J. Woessner (2012), Estimating the magnitude of completeness for earthquake catalogs, Community Online Resource for Statistical Seismicity Analysis, http://www.corssa.org.

Nam, T.N. (1995), The geology of Vietnam: A brief summary and problems, Geosci. Rep. Shizuoka Univ. 22, 1-10, DOI: 10.14945/00000334.

Peterson, J. (1982), GDSN enhancement studies final report, ARPA Order No. 4295, USGS Albuquerque Seismological Laboratory, Albuquerque, USA.

Phach, P.V., and V.V Chinh (1995), Report on structure/tectonic for Cenozoic and relationship with seismicity on territory of Vietnam, Archives of the Institute of Geophysics, VAST, Hanoi, Vietnam (in Vietnamese).

Shi, Y., and B.A. Bolt (1982), The standard error of the magnitude-frequency b-value, Bull. Seismol. Soc. Am. 72, 5, 1677-1687.

Simpson, D.W. (1976), Seismicity changes associated with reservoir loading, Eng. Geol. 10, 2-4, 123-150, DOI: 10.1016/0013-7952(76)90016-8. 
Simpson, D.W. (1986), Triggered earthquakes, Ann. Rev. Earth Planet. Sci. 14, $21-$ 42, DOI: 10.1146/annurev.ea.14.050186.000321.

Simpson, D.W., W.S. Leith, and C.H. Scholz (1988), Two types of reservoirinduced seismicity, Bull. Seismol. Soc. Am. 78, 6, 2025-2040.

Son, L.T. (1995), The approximation of seismic velocity model for Vietnam territory. In: Proc. Fourth National Conference on Physics, 5-8 October 1993, Hanoi, Vietnam, 651-655 (in Vietnamese, abstract in English).

Thuy, N.N., P.V. Phach, V.V. Chinh, L.H. Minh, P.D. Nguyen, P.Q. Hung, and N.A. Duong (2003), Report on estimation of the seismic design for the Song Tranh 2 hydropower construction, Archives of the Institute of Geophysics, VAST, Hanoi, Vietnam (in Vietnamese).

Trojanowski, J., B. Plesiewicz, and J. Wiszniowski (2015), Seismic monitoring of Poland - description and results of temporary seismic project with mobile seismic network, Acta Geophys. 63, 1, 17-44, DOI: 10.2478/s11600-0140255-0.

Wiejacz, P. (1992), Calculation of seismic moment tensor for mine tremors from the Legnica-Głogów Copper Basin, Acta Geophys. Pol. 40, 2, 103-122.

Wiemer, S., and M. Wyss (2000), Minimum magnitude of completeness in earthquake catalogs: Examples from Alaska, the Western United States, and Japan, Bull. Seismol. Soc. Am. 90, 4, 859-869, DOI: 10.1785/0119990114.

Woessner, J., and S. Wiemer (2005), Assessing the quality of earthquake catalogues: Estimating the magnitude of completeness and its uncertainty, Bull. Seismol. Soc. Am. 95, 2, 684-698, DOI: 10.1785/0120040007.

Wyss, M., A. Hasegawa, S. Wiemer, and N. Umino (1999), Quantitative mapping of precursory seismic quiescence before the 1989, M7.1 off-Sanriku earthquake, Japan, Ann. Geofis. 42, 5, 851-869.

Received 15 December 2014

Received in revised form 20 February 2015

Accepted 10 March 2015 